\title{
Parotid Gland Carcinosarcoma
}

National Cancer Institute

\section{Source}

National Cancer Institute. Parotid Gland Carcinosarcoma. NCI Thesaurus. Code C35832.

An aggressive, high grade malignant tumor that arises from the parotid gland. It is characterized by the presence of a malignant epithelial and a sarcomatous component. 